\title{
FROM STYLES 0 TO STYLE E-0. COGNITIVE STYLES IN E-LEARNING
}

\author{
María Rosa Pinto Lobo \\ Faculty of Communication. Pontifical University of Salamanca \\ Salamanca, Spain.
}

\begin{abstract}
The question posed by e-learning is that it does not always comply with any of the characteristics that define the process of interpersonal communication according to the classical paradigm, for example, sharing space and time and/or knowing the agents receiving the communicative process. The non-shared space-temporal variables imply a difficulty processing the information from the styles or cognitive styles of the last century for both the teacher and the student. We propose a new style of knowledge: the e-0 style. This style is developed in a virtual space. Its objective is to ensure that the transmission of information becomes knowledge with the same effectiveness as with face-to-face teaching-learning.
\end{abstract}

\section{KEYWORDS}

Styles 0, e-0 Style, Communication, Knowledge, e-Learning, Learning

\section{INTRODUCTION}

Learning e-learning is a communication process that does not always comply with all the characteristics that define interpersonal communication. If we stop at space and time dimensions we can observe that on many occasions they are not shared. This presents a difficulty in processing information from the cognitive styles of the sending agent and the receiving agent, whether teacher or student.

During the twentieth century, studies on cognitive styles, known as the styles of the zero years, were published because the research was published in 1950, 1960 and 1970. In 1950 the work on the authoritative cognitive style of Theodor Adorno appeared. (1950). In 1960, Milton Rokeach (1960) offers us his contributions to dogmatic style and open-minded style. Richard Christie and Florence Geis (1970) present the characteristics of the Machiavellian style in the seventies. All these cognitive styles allow us to study the processes of communication and learning, with an adaptation of the teacher to the students or vice versa.

\section{FROM STYLES O TO STYLE E-0}

The cognitive style is the way the subject has to respond to information that comes from outside. How do we respond to the avalanche of information that we receive every day through the multiple screens that populate our communicative universe? The response we give to the informative exposition depends on the style of knowledge we develop. In face-to-face learning processes, cognitive styles manifest themselves in a physical space and in a time-shared by communicative agents. The teacher can adjust and redefine his style to the knowledge styles of the students with whom he shares the classroom and the student can do it in the same way.

\subsection{Styles 0}

Cognitive styles are also known as styles 0 or styles of years zero. The publications of the results of the investigations were, as we have already indicated, in the 1950s, 1960s, 1970s. An exhaustive exposition of these styles can be found in the General Information Theory (Valbuena, 1997: 145-154). 
Authoritarianism was studied by Adorno (1950) and his collaborators at the Frankfurt School. The authoritarian subject shows submission to the people who hold power. They do not make value judgments or criticisms of the authority. It moves in the context of conventional norms accepted by the group. Reject people who do not follow these rules. It does not accept subjectivity or opinions that are contrary to those established by the authority, which in many cases is considered a predestined person. He sees the world as threatening and with conspiracy subjects with destructive objectives. It only perceives the most negative of the human being.

Dogmatism or the closed-minded subject was studied by Milton Rokeach (1960). For this researcher, the response to external information that characterizes the authoritarian is not only limited to individuals of a certain ideology, fascism, as underlined by Adorno but can correspond to individuals of any ideology. Rokeach added the reverse side of the dogmatic or closed-minded subject and showed us the characteristics of the open-minded cognitive style.

The open-minded subject admits conflicting information from the outside. He is able to rectify because he does not mind questioning his own positions if circumstances have changed. It does not have rigid categories, which allows it to establish nuances and exceptions to the rules. Believe more in the strength of reasoning than the power of authority. The open-minded style emphasizes that respect is earned while authority prevails. It is not against authority because it is the authority. He respects it, but the open-minded subject knows how to be autonomous and decide for himself. It recognizes the authority for the information and experience it may have but does not need it to act. Has the ability to see the positive potential of people.

The researchers realized that a group of people did not respond to stimuli and external information according to the characteristics discussed so far. Richard Christie and Florence Geis (1970) exposed the characteristics of another cognitive style known as Machiavellian style or Machiavellianism. The name comes from the characteristics that we can find in works like The Speech and The Prince of Machiavelli.

The Machiavellian subject is a manipulative subject, who uses others to achieve their ends. Thus, the end justifies the means, although in these media is the immoral employment of people. The Machiavellian has no feelings towards others. It treats people as objects and does not identify with them so as not to lose their objective. It is not guided by moral criteria, but utilitarian. The Machiavellian subject is a great information processor and he uses this always in his benefit for the achievement of his ends. He is not an idealist, but a very practical and versatile subject, capable of adopting any ideology or none when circumstances require it. He knows how to move very well in situations of uncertainty and chaos. Do not be afraid of confusing situations.

In a traditional teaching-learning process in the classroom, in which space and time are shared, it is possible to identify each of the styles of knowledge and, therefore, perform an emission/reception of the information that allows the subject to adjust to the cognitive style of the other agents. What happens if the teacher and the student do not know each other? How are cognitive styles identified in virtual spaces? How do we get the e-learning teaching-learning process to be effective?

\subsection{Methodology}

The methodology used to propose the e- 0 style has been a qualitative inductive methodology. The approach is exploratory, observational, prospective and comparative. It starts from consolidated concepts, exposed in section 2.1 Styles 0, and these concepts are related for describing the quality of a new construct, the cognitive style: e- 0 . In this way, we reduce the complexity of the teaching-learning process in a virtual environment to our object of study: teacher-student interaction with a style cognitive own e-learning. It is the virtual environment that modifies the conceptual relationship that occurs in face-to-face processes and generates the coherence of the proposal that requires scientific rigor.

The teaching experience of three decades makes it easier for us to use a constructivist paradigm and an interpretive paradigm. The first, the constructivist paradigm, with a hermeneutic and dialectical methodology, entails the result of the research and reflection presented here. This result is created by the same process and experienced by the observer. The results are reinforced from the interpretative-participant methodology. The interpretation is carried out from the experience in face-to-face and virtual teaching in the university environment. 


\subsection{Results. The Style e-0}

The search for similarity and the difference between styles 0 in face-to-face teaching and virtual learning leads to results that imply the construction of a new style of knowledge for the teacher and for the student. We are before a qualitative study of action research, oriented to a change in the interpersonal relations of the agents that intervene in the process.

In face-to-face teaching, the cognitive style of the teacher can be adjusted to each of the student's knowledge styles and vice versa. However, we must know what cognitive style is the one that stimulates students to learn and acquire knowledge when teaching, for example, with Blackboard Collaborate to unknown students, and they follow the sessions on platforms such as Moodle at any time This is an interesting line of research that has been developing in recent years (Fatai, 2019, Merchán, 2018, Morado, 2018 and Valencia-Vallejo, 2018).

The case studied, therefore, is that of individual learning of students unknown to the teacher. The sessions are virtual with Blackboard Collaborate through the Moodle online platform. For the elaboration of these sessions, it is necessary that the interaction contemplate characteristics of all the styles 0 . This allows identification of the student, whatever their style, with the teacher. This facilitates the acquisition of knowledge. For the issuer supposes to recompose the style that defines him according to the virtual context in which the classes are taught. The teacher and the student no longer have an interaction with any of the styles 0 described, but the interpersonal relationship is reached with the homogeneity of the e- 0 style that is shared by all the agents.

The e- 0 style is the synthesis of the features that characterize cognitive styles. The context and content that determines this virtual context are taken into account for the synthetic process, according to the dialectical method.

The thirteen characteristic features of the e- 0 style are: admission of all types of information; ability to rectify and question different positions; primacy of reasoning; recognition of authority without submission; assessment of autonomy; interest in the nuances; originality versus conventionalism; understanding towards the different; multiple and plural view of the events versus the dichotomous vision; appreciation of subjectivity, creativity, aesthetics; assessment of the emotional aspect of interpersonal relationships; application of ethical judgments to dilemmas and decision making; commitment to moral values.

Each of the features of the e- 0 style refers to the front or back of a style. All the features of the e- 0 style allow, in a virtual environment, to move from mere information to knowledge. These features facilitate the teacher-student interaction and with it the intellectual and emotional action of the individual who wants to learn and acquire knowledge.

\section{CONCLUSION}

The e- 0 style synthesizes the characteristics of the different styles of knowledge: authoritarian-dogmatic style, open-minded style and Machiavellian style.

The conjunction of features that characterize the e- 0 style allows the information to be processed correctly in a virtual environment. In this virtual environment, all the characteristics that define interpersonal communication according to the classical paradigm are not always present.

The features of the e- 0 style have to be shared by all agents of the teaching-learning process to achieve an effective teacher-student interaction in a virtual space.

The e-0 style proposal is the result of participatory and exploratory observation, with a prospective and comparative nature. This result, the reason for the reflection that has been presented here, requires future research that corroborates the need to apply this style to improve the educommunicative processes of the $21 \mathrm{st}$ century.

It continues, with this proposal, an interesting line of research that deals with and concerns all those involved in the communication process, whatever the medium in which the exchange of teaching and learning takes place. 


\section{ACKNOWLEDGEMENT}

To Octavio Aguilera Perelló, journalist, teacher and, forever, friend. Porto, 2019.

\section{REFERENCES}

Adorno, T. et al, 1950. The Authoritarian Personality. Harper and Row. New York, USA.

Aguilera, O., 1998. El proceso creativo. Fragua, Madrid, España.

Christie, R. et al, 1970. Studies in Machiavellianism. Academic Press, New York, USA.

Fatai, S., 2019. An experimental study on an adaptive e-learning environment based on learner's personality and emotion. Education and Information Technologies. 17 pp. Available in: https://doi.org/10.1007/s10639-019-09868-5. [Viewed: 3-03-2019].

Merchán, C.A., 2018. Modelamiento pedagógico de Ambientes Virtuales de Aprendizaje (AVA). Revista de la Facultad de Ciencia y Tecnología, No. 44, pp 51-70.

Morado, F., 2018. Entornos virtuales de aprendizaje complejos e innovadores. Revista Electrónica Educare, Vol. 22, No. $1, \mathrm{pp} 1-17$.

Pastor, G., 1982. Síndrome frío de personalidad sagaz. Universidad Pontificia de Salamanca, Salamanca, España.

Pinto, M.R., 2018. Comunicación e inteligencia artificial. Propuesta del modelo de comunicación BS. VI Congreso Internacional de la AE-IC. Comunicación y Conocimiento. AE-IC. Salamanca, España, pp. 83-103.

Rheingold, H., 1994. Realidad virtual: Los mundos artificiales generados por ordenador que modificarán nuestras vidas. Gedisa, Barcelona, España.

Rokeach, M., 1960. The Open and Closed Mind. Investigations into the Nature of Beliefs Systems and Personality Systems. Basic Books Inc. Publishers, New York, USA.

Siddique, A., et. al, 2018. Developing Adaptive E-Learning Environment Using Cognitive and Noncognitive Parameters, Journal of Educational Computing Research. Available in: https://journals.sagepub.com/doi/full/10.1177/0735633118769433 [Viewed: 6-03- 2019].

Valbuena, F., 1997. Teoría General de la Información. Editorial Noesis, Madrid, España.

Valencia-Vallejo,N. et. al, 2018. Efect of Motivational Scaffolding on E-learning Evironments: Self-efficacy, Learning Achievment, and Cognitive Style. Journal of Educators Online, Vol. 15, No. n1, 14 pp. 